\title{
EPILOIA AND ENDOCARDIAL FIBRO-ELASTOSIS
}

\author{
BY \\ L. CROME \\ From the Neuropathology Department, the Fountain Hospital, Tooting, London
}

(RECEIVED FOR PUBLICATION DECEMBER 7,1953 )

There has been some revival of interest recently in the condition known formerly as 'foetal endocarditis', and now as endocardial fibro-elastosis, and the subject has been well reviewed by Gowing (1953). It is believed to be characterized by progressive heart failure in infants and young children, presenting at necropsy cardiac hypertrophy and endocardial thickening produced by an increase in its fibrous and elastic tissue constituents.

The purpose of this communication is to record two cases of epiloia in which similar endocardial fibro-elastosis was found at necropsy. Two other cases of epiloia, in a series of 120 necropsies upon mentally defective children of lower grade, were without this change.

\section{Case Reports}

Case 1. The patient was illegitimate with a normal half-sister, three years older. Nothing is known of the father, but the patient's mother and her family had no neurological or mental disease. The mother was an unskilled factory hand, poor, with housing and domestic difficulties. During the pregnancy she was admitted to hospital for 'kidney trouble' well before confinement, remained an in-patient for three months following it, and died some months later. No further details are available.

Delivery was by lower segment Caesarean section. A week after birth it was noticed that the infant could not swallow and a throat swab was positive for diphtheria. The patient's backwardness was observed in early infancy. He sat up at 3 years but did not smile, walk or talk. At 7 months he was vaccinated and the first epileptic fit was seen then. The fits were frequent in later years, some being described as grand mal and others as petit mal, and he remained mentally an unresponsive idiot. At 10 years he had a prolonged respiratory illness diagnosed as an unresolved pneumonia or, possibly, tuberculosis. Shortly before his death from bronchopneumonia at 14 years, early adenoma sebaceum was noticed on his face and the diagnosis of epiloia was made.

Pathological Findings. There was gross emaciation with pigeon chest. Barely visible adenoma sebaceum was present on the face without other skin lesions.

The heart was somewhat enlarged, weighing $202 \mathrm{~g}$. Several flat lipomata were present on its surface near the apex penetrating well into the substance of the myocardium. The left ventricle was hypertrophied (Fig. 1), its wall measuring $2 \cdot 1 \mathrm{~cm}$. in its thickest portion. The endocardium was thickened in the left auricle, near the left ventricular surface of the inter-ventricular septum, and also over some of the chordae tendineae of the mitral valve. A firm oval nodule (Fig. 2) measuring $8 \times 5 \mathrm{~mm}$. projected into the right ventricle from the endocardium, and multiple irregular pale areas of tissue varying in size from less than $1 \mathrm{~mm}$. up to $4 \mathrm{~mm}$. could be seen within the heart muscle.

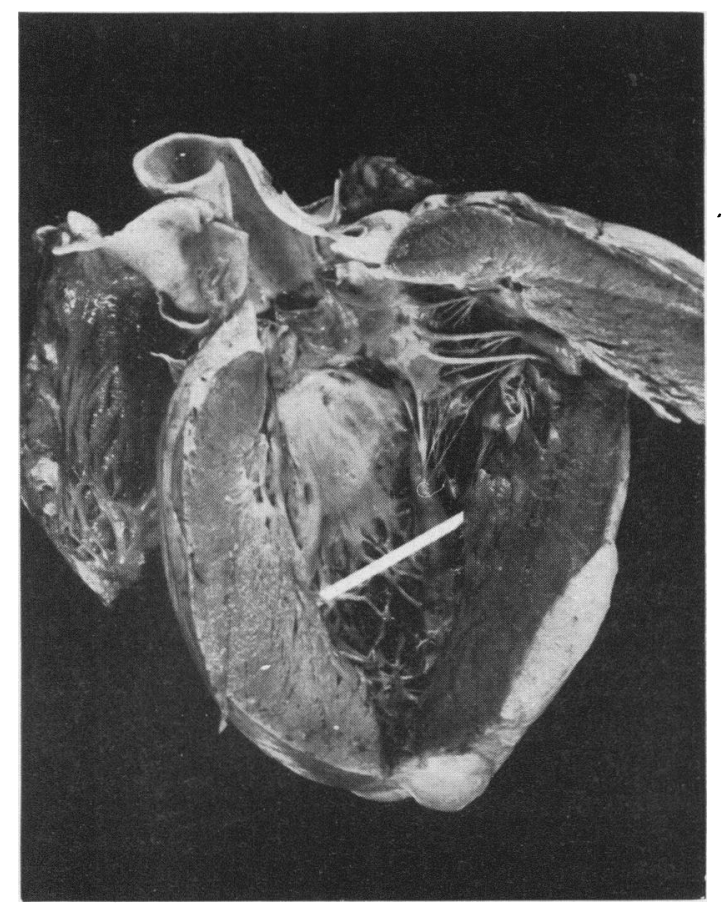

Fig. 1.-The left ventricle is hypertrophied, the endocardium is thick and opaque. Lipomata are present in the lower part of the heart. 


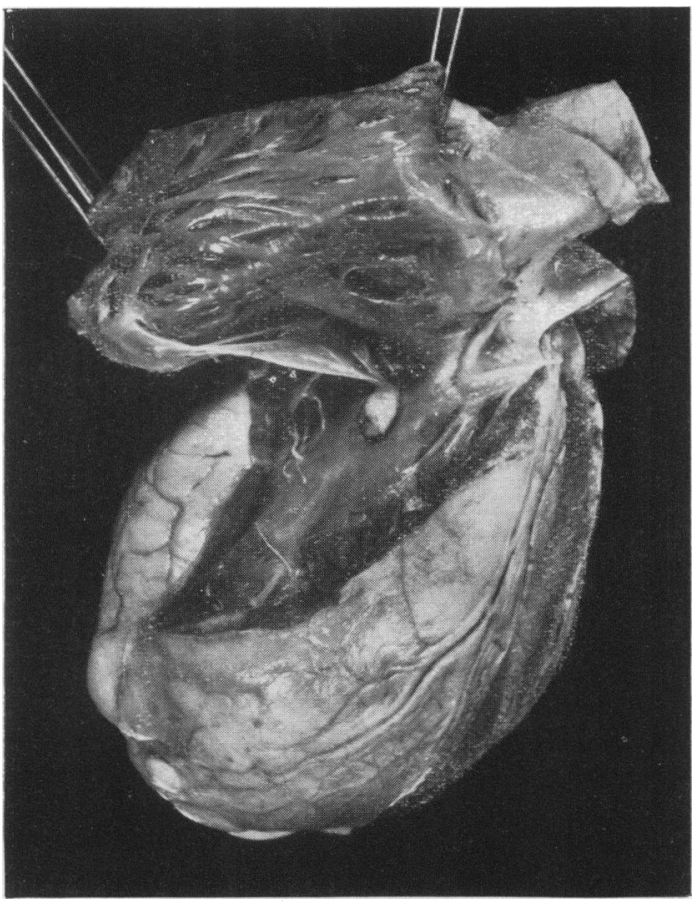

Fig. 2.-Purkinjeoma projecting into the right ventricle.

The right lung was firmly adherent to the chest wall, and the cut surface of both showed a pattern of oedema, consolidation and lobular collapse. Fairly numerous tubercles were also found in both lungs and there was, in addition, peripherally in the upper part of the right middle lobe an area $5 \times 3 \mathrm{~cm}$. comprising many contiguous and fairly large cysts with more widely scattered smaller discrete cysts (Fig. 3).

The brain $(1,410 \mathrm{~g}$.) and other parts of the central nervous system were of normal size with no macroscopic abnormality. Numerous hard nodules were palpable, however, within the cerebral hemisphere and these became visible later after formalin fixation and the

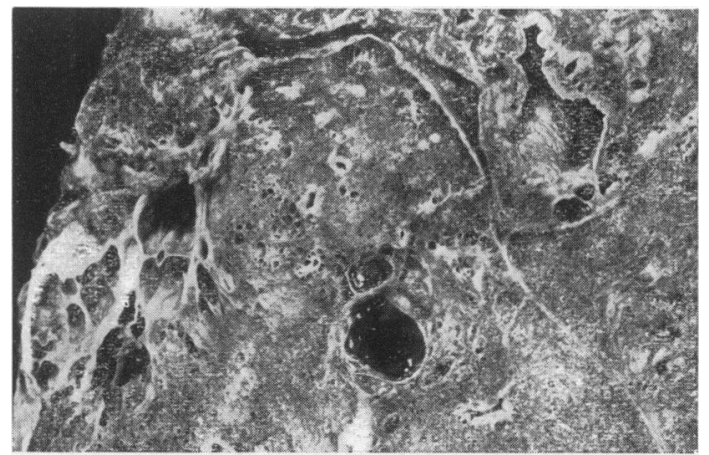

FIG. 3.-Large contiguous and smaller discrete cysts in the right lung. removal of the meninges, as somewhat pale portions of the gyri with a coarsely granular surface. An x-ray photograph of the brain showed that many of them were calcified (Fig. 4). Many white, hard, elongated and tortuous nodules-'candle gutterings'-were seen projecting into the lateral ventricles when the brain was cut in coronal sections (Fig. 5).

Microscopical Examination. All organs were fixed in formalin and later embedded in paraffin and celloidin, frozen sections being also used for fat staining and silver impregnation. The customary general and neurological staining methods were employed and some of these will be indicated below together with the relevant findings.

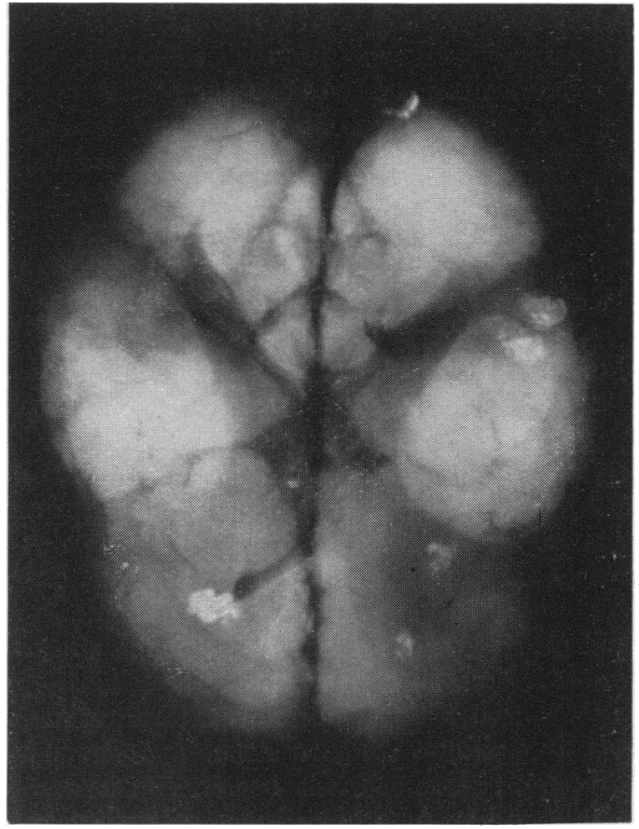

FIG. 4.-Radiograph of the brain showing dilatation of the ventricles and calcified nodules.

The larger nodules were well seen in Nissl sections of the brain as pale areas in which cortical lamination was obliterated (Fig. 6). Corresponding sections stained by the Holzer method showed the lesions as dark foci of dense fibrous gliosis in the cortex with or without extension into the subjacent white matter. More discrete nodules were also present in the centrum semiovale. The nodules were distributed evenly and in a seemingly haphazard manner throughout the cerebral hemispheres.

The nerve cells were greatly reduced in the cortical lesions, those remaining being pyknotic, shrunken and, frequently, orientated at unusual angles. Many nerve cells stained very faintly while others were abnormally large. Silver impregnation, such as Bielschowsky's, showed numerous tortuous or angular fibrils running from the cells at unusual angles and in many different directions. The glial cells were increased in number, most of them being fibrillary astrocytes. Other glial cells had 


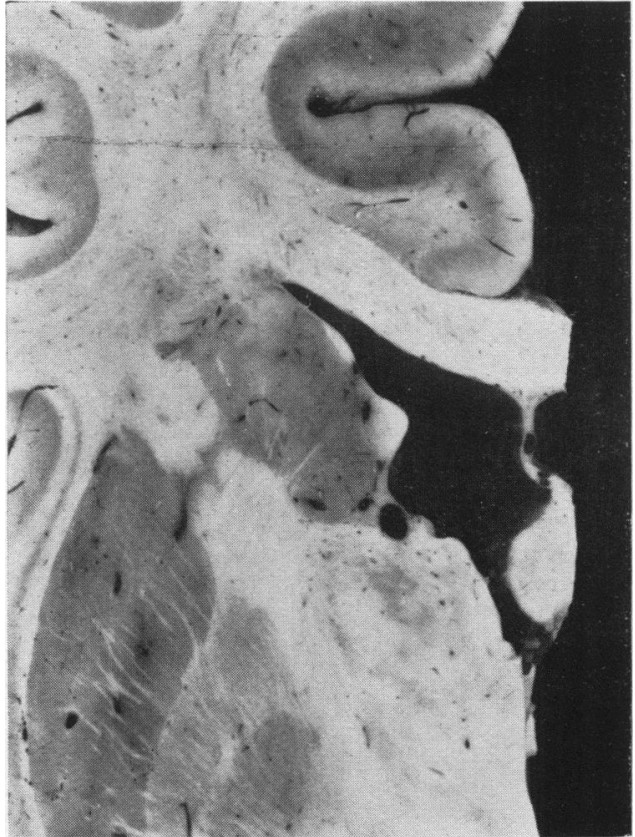

Fig. 5.-Subependymal nodules of 'candle guttering' in the lateral ventricle.

protoplasmic cytoplasm with irregular cell outlines. Some of the latter were distinguished by their strikingly large size (Fig. 7), homogeneous opaque cytoplasm and oval- or kidney-shaped nuclei which were peripheral and, sometimes, multiple. These cells were particularly numerous in the subcortical gliotic nodules. Microglial cells were also increased in number in some of the nodules. The silver impregnation methods, though effective, proved somewhat unreliable as a guide to the identity of the adventitious cells, methods recommended

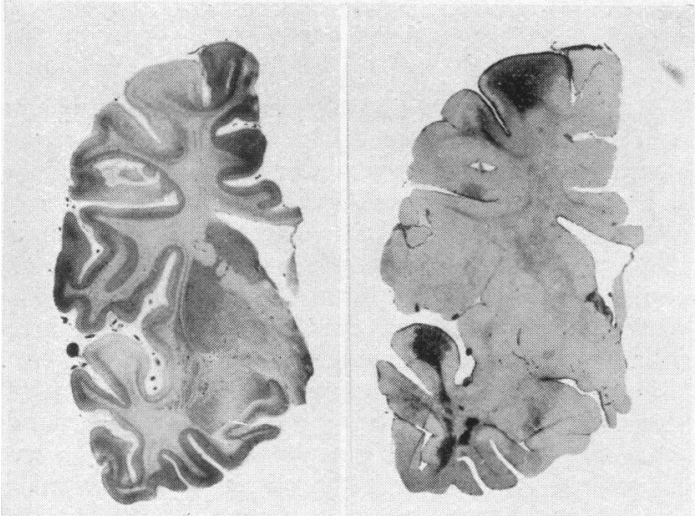

Fig. 6.-Coronal section of the left cerebral hemisphere stained by the Nissl method, left, and Holzer method, right. Obliteration of cortical pattern and areas of dense fibrous gliosis. for demonstrating one type tending easily to impregnate others. It was, furthermore, impossible to decide for many of the abnormal cells whether their origin was glial or neuronal.

The myelin sheaths and axon cylinders were reduced in number within the affected areas and showed many degenerative changes such as beading, tortuosity and fragmentation.

The bulk of the gliotic nodules consisted of a dense irregular feltwork of glial fibres. The density varied from nodule to nodule and, within each, in a manner defying generalized description. Many possessed, however, three identifiable zones of gliosis: a superficial one occupying a layer 2-3 $\mathrm{mm}$. in depth parallel with the cortical surface, an intermediate one of equal depth in which gliosis was less dense, and a third deep one which

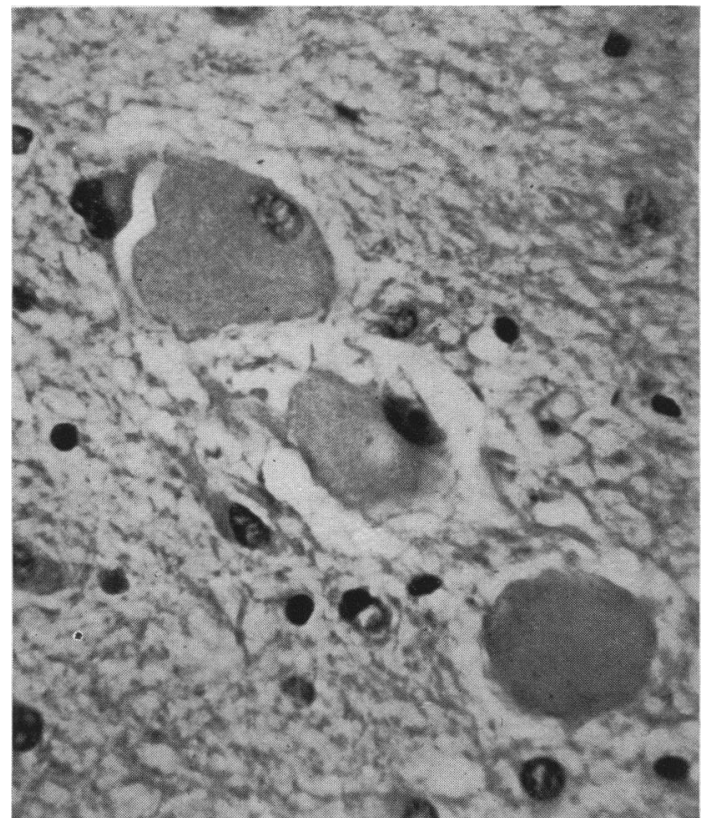

Fig. 7.-Large globoid cells in gliosed nodules of white matter. Haematoxylin and eosin $\times 500$.

extended for a variable distance into the underlying white matter.

Many round or oval calcified granules, $15-20 \mu$ in diameter, were present in the gliotic nodules, particularly numerous round some of the blood vessels.

The histological structure of the subcortical nodules did not differ substantially from that of the cortical ones save for the absence in the former of readily identifiable nerve cells though some contained a few large adventitious cells the identity and origin of which was doubtful.

The subependymal nodules of the 'candle guttering' were distinguished by their cellularity, many of their cells being rather uniform, large and elongated with oval or kidney-shaped vesicular nuclei and cylindrical or tapering cytoplasm. Some small, festooned ependymal nodules 


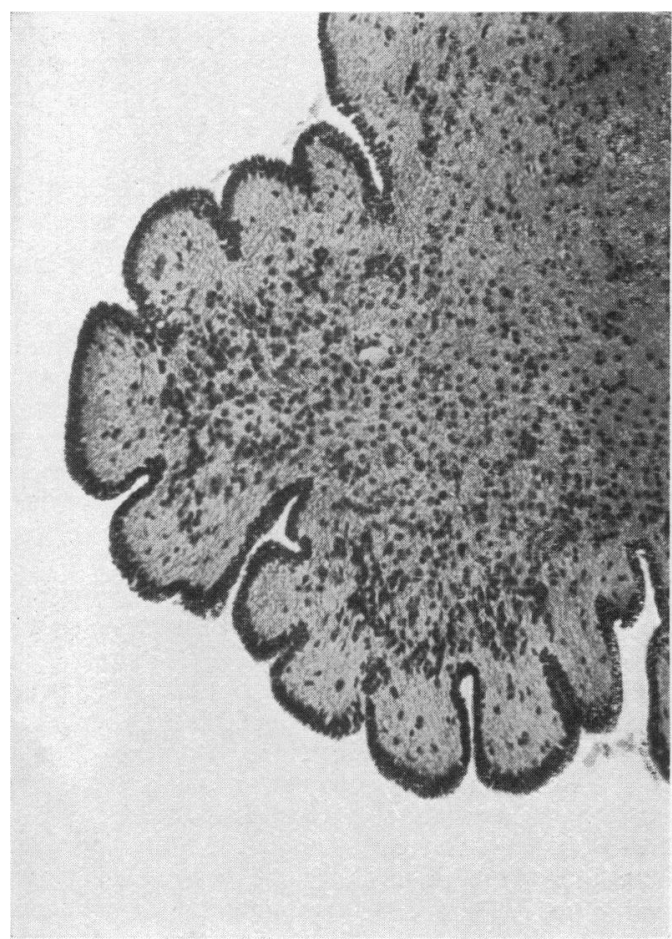

Fig. 8.-Festooned nodule projecting into the ventricle. Haematoxylin and Van Gieson. $\times 120$.

were also present in the ventricles and these contained dense glial fibres and uniform fibrillary astrocytes (Fig. 8).

In addition to the characteristic areas of gliosis described above, diffuse fibrous gliosis without marked demyelination or cellular change was present in the marginal layers of the cerebrum away from the nodular lesions, around the periphery of the brain-stem and spinal cord, around the inferior olives and the gray matter of the spinal cord and in parts of the molecular layer of the cerebellum. The latter showed also some atrophy of the Purkinje and granular layers.

The thickened endocardium consisted of rather acellular strands of collagen interspersed by reticular elastic tissue (Fig. 9). While the fibro-elastosis was confined to the endocardium over the greater part of the affected area, the subjacent muscle was also involved in it in a few places.

The nodule projecting into the right ventricle and the pale smaller areas situated within the heart muscle were found to be identical with the debatable structures usually referred to as 'rhabdomyomata'. They consisted of a solid mass of large cells each of which had a round central nucleus and cytoplasm which was either entirely absent or else arranged in radial or tangential fibrils and bundles of fibrils. Some of the latter showed distinct transverse striation particularly when stained with Heidenhain's haematoxylin (Fig. 10). In addition to the tumour-like proliferation of these cells in the situations

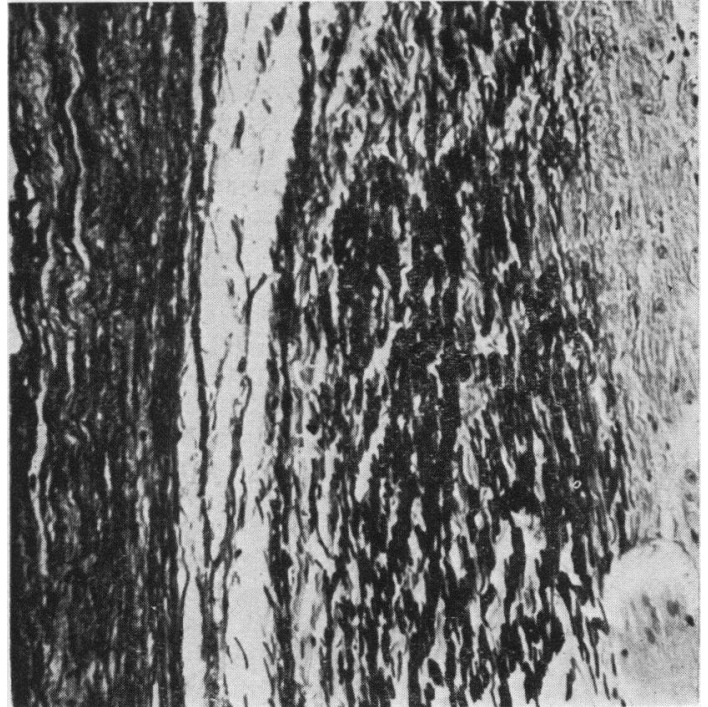

FIG. 9.-Fibro-elastic tissue in endocardium and subjacent muscle. Verhoeff's elastic tissue stain and Van Gieson. $\times 120$.

described above, they were also distributed singly or in small clusters under the fibro-elastic layer of the endocardium and within small irregular areas of fibrous tissue in the heart muscle itself.

The large lipomata seen on the surface of the heart were formed by adipose tissue of normal appearance.

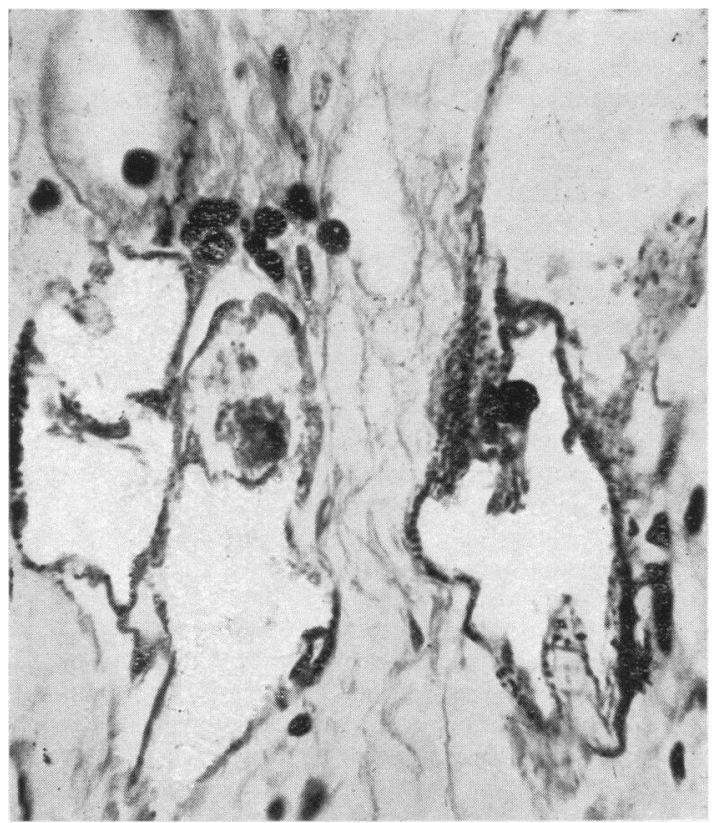

FIG. 10.-Large 'empty' cells of Purkinjeoma with transverse striation near the cell border. Heidenhain's haematoxylin. $\times 180$. 
Sections of the facial skin taken from the area of adenoma sebaceum showed some hyperkeratosis and irregular thickness of the Malpighian layer. The rete pegs lacked uniformity; many were excessively long and thin, others were flattened. The dermis was thickened owing mainly to an increase in its fibrous tissue. There was also some increase in the number and size of the sebaceous and sweat glands.

Many of the tuberculous lesions in the lungs showed caseation beginning in the centre. The areas of pneumonic consolidation contained polymorphonuclear leucocytes with numerous phagocytic cells, having granules and globules of albuminous or fatty material within their cytoplasm. Some of these phagocytic cells were multinucleated. Other sections of the lungs confirmed the nakedeye impression of lobular collapse and oedema. The cystic cavities mentioned in the naked-eye description of the lungs were twofold in structure. Some were bronchiectatic having walls formed by fibro-muscular tissue, mucous glands, fat and cartilage and lined by a single layer of columnar ciliated epithelium. Others were greatly dilated venous spaces. Lymphatic tissue within the cystic area contained a few tuberculous lesions. These were, however, like the other tuberculous lesions discrete, and the cystic cavities did not appear to be secondary to tuberculosis.

Case 2. The patient, the only child of young working class parents whose families were free of mental or nervous disease, was born after a normal pregnancy and confinement, and weighed $6 \frac{3}{4} \mathrm{lb}$. A naevus measuring $1 \times 2 \frac{1}{2} \mathrm{~cm}$. was present upon her left lower eyelid but she appeared otherwise normal. She had an epileptic convulsion at the age of 4 months when she was seen to clench her fist and her body to stiffen. Fits recurred frequently after that, some being described as major and others as minor, and she had, in addition, frequent prolonged screaming attacks. She was slow in passing the normal landmarks of development and remained incontinent of urine and faeces. At the age of 4 , on admission to the Fountain Hospital, a few pink spots were seen on her face as well as the naevus. A radiograph of the skull showed no intracranial calcification and the condition was diagnosed as epiloia or central neurofibromatosis. She could hear loud noises and see objects but did not react to speech and no contact could be established with her. She was hyperactive in her cot, exhibiting purposeless movements of head and limbs. She was able to take food to her mouth but remained completely incontinent and tended to eat faeces. Her tendon reflexes were normal. The psychologist's report read as follows:

'She was restless and moved around her cot continually; she could sit, stand and walk alone. She turned to investigate the sound of a bell, grasped it and rang it herself. She showed no dominant handedness. It was not possible to determine whether she understood anything that was said to her. She made no attempt to imitate the construction of a tower or any other simple activity, but handled the bricks and ball in aimless fashion. She made no attempt to talk but uttered harsh cries and grunts.
Her developmental age on the Vineland Maturity Scale is approximately 9 to 10 months and she would appear to be of idiot-imbecile level.'

The patient died two months after admission following respiratory illness.

Pathological Findings. The body was that of a very thin girl with many excoriations on both forearms and hands. The facial naevus could be recognized but not the adenoma sebaceum.

The heart was normal in size (65 g.), several small lipomatous nodules being present upon the epicardium. The endocardial surface of the left auricle and of the left side of the interventricular septum were somewhat thickened and opaque, this change being less marked than in Case 1. A hard, indurated area of fibrous tissue replaced, in addition, the endocardium, the columnae carneae and part of the myocardium at the apex of the left ventricle.

The trachea and bronchi were inflamed and the cut surface of the lungs showed bronchopneumonia and a number of small abscesses.

Some small cysts measuring up to $2 \mathrm{~mm}$. in diameter were present upon the surface of the kidneys. The renal cut surface revealed the presence of many irregular areas up to $8 \mathrm{~mm}$. in size in which the normal pattern was replaced by uniform white homogeneous tissue.

The meninges were greatly congested. Many irregular hard nodules were palpable in the brain, which was normal in size $(1,290 \mathrm{~g}$.). They were more numerous than in Case 1, leaving little of the intervening cerebral substance free and of normal consistency. These nodules showed themselves, once more, as paler and coarser portions of the gyri after the brain was fixed and the meninges stripped. 'Candle guttering' was likewise present in the lateral ventricles.

Numerous small areas in which brain tissue was replaced by somewhat translucent, gelatinous, greyish material were seen in the white matter of the cut brain. Most of these measured less than $1 \mathrm{~mm}$. and were round, oval or lineal suggesting vascular or perivascular distribution; the largest measured $3 \mathrm{~mm}$. in diameter.

The brain-stem, cerebellum or spinal cord showed no naked-eye abnormality.

Microscopical Examination. The material was prepared as in the previous case and the histological findings being, in the main, identical, attention will be given in the description below to changes differing from those in the former.

The cortical gliotic nodules had a greater number of large adventitious nerve cells (Fig. 11). Although, as mentioned already, no calcification was seen on x-ray examination, many calcified particles were, nevertheless, present in the nodules, particularly, the subependymal ones of 'candle guttering'.

In contrast to the first case, some gliotic nodules were also present in the reticular substance of the medulla and in the cerebellum, being situated, within the latter, in the most peripheral portions of its middle lobe. These cerebellar nodules consisted of a dense proliferation of fibrous glia in the molecular layer with a relatively slight increase in astrocytes. The Purkinje cell layer was 


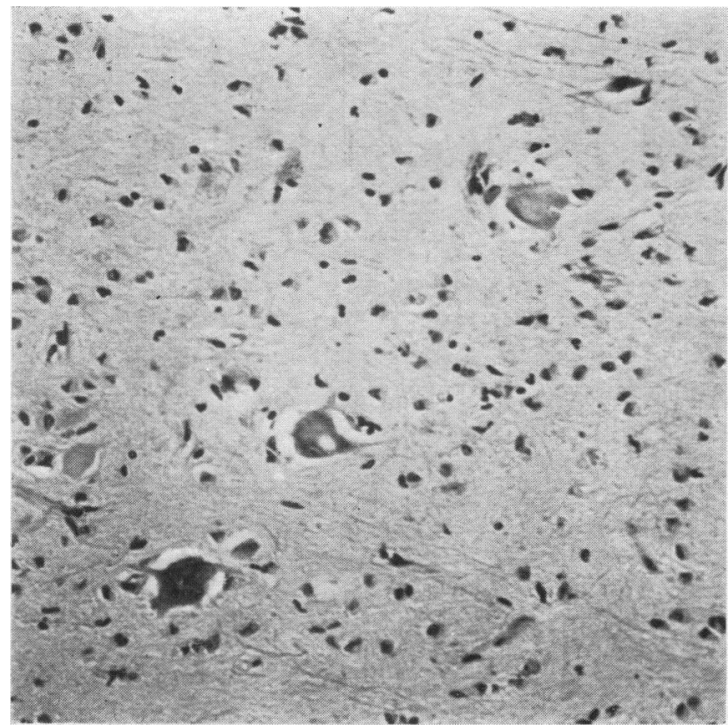

FIG. 11.-Cerebral cortex showing large distorted nerve cells and an increased number of glial cells. Haematoxylin and Van Gieson. $\times 180$.

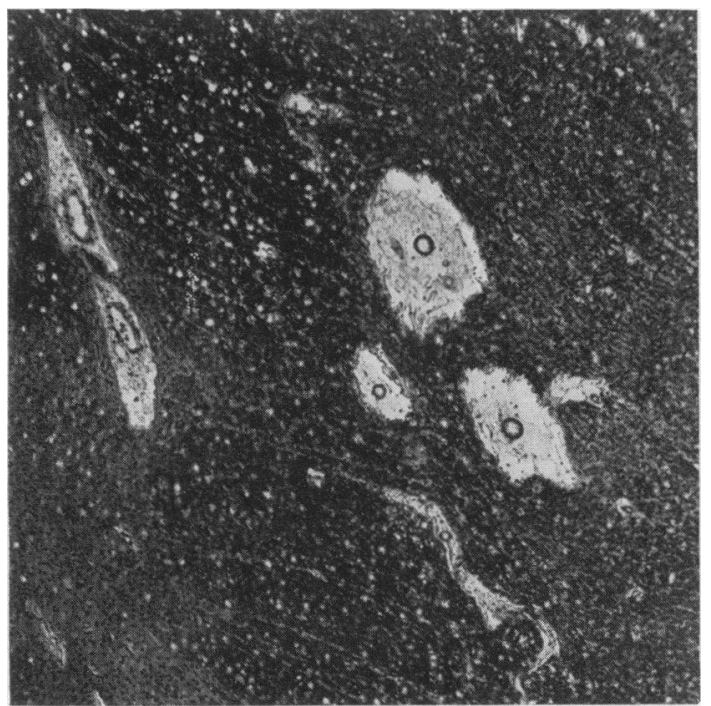

FIG. 13.-Perivascular reticulation of cerebral white matter. Haematoxylin and Van Gieson. $\times 180$.

occupied by a large number (Fig. 12) of elongated large cells set in palisade fashion next to each other. These appeared to be modified Purkinje cells, as it was possible to trace transitional forms between the two types at the junction of the gliotic and normal tissue. The granular layer showed considerable atrophy and gliosis while the white matter was almost completely replaced by glial tissue.

The 'gelatinous' foci of the cerebral white matter

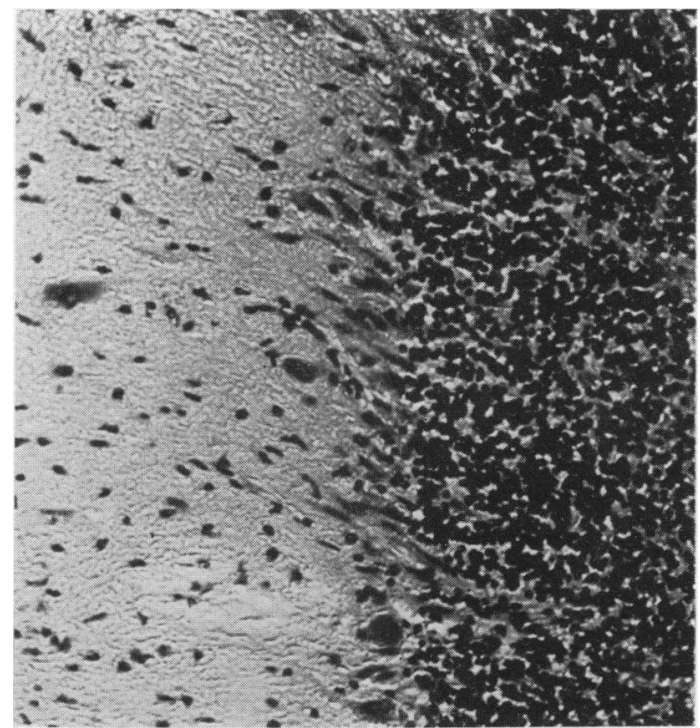

Fig. 12.-Cerebellum with abnormal Purkinje cells. Haematoxylin and eosin. $\times 180$.

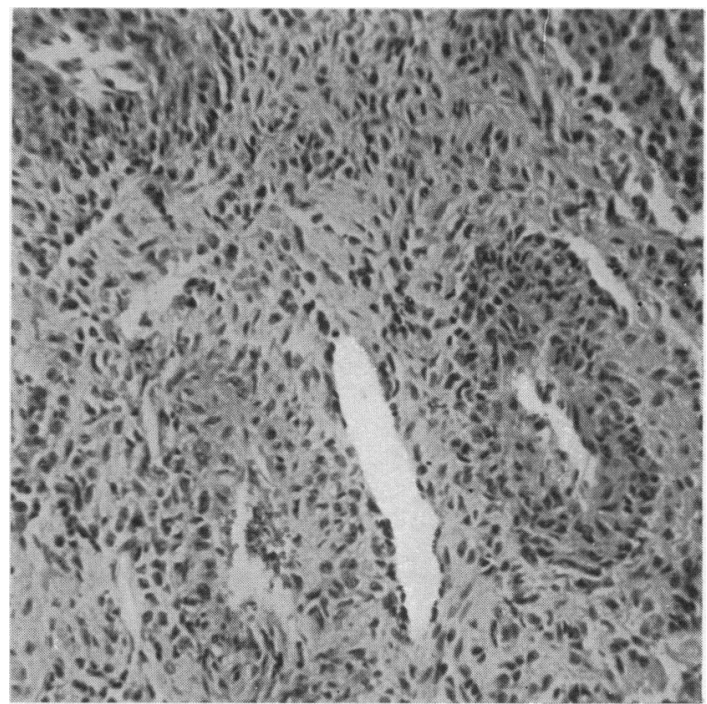

Fig. 14.-Endothelio-fibroma of kidney. Haematoxylin and eosin. $\times 180$.

presented as areas of perivascular reticulation, lacunation and adventitial hypertrophy (Fig. 13). The normal tissue around the blood vessels was replaced by a loose network of collagen and reticulin fibres, with a few compound granular corpuscles lying within its meshe. . Some of the blood vessels in the centres of the affected areas showed hyaline degeneration.

The endocardial changes were similar but less marked than in the first case. Although not visible to the naked 
eye, microscopical clusters and nodules of 'rhabdomyomatous' heart cells were present under the endocardium and within fibrotic areas situated between myocardial fibres.

Examination of the lungs confirmed the naked-eye findings of bronchopneumonia and suppuration.

The abnormal tissue in the kidneys was formed by a solid mass of rather uniform spindle-shaped or curled cells with vesicular or rod-shaped nuclei (Fig. 14). The blood vessels of this tissue had greatly thickened walls

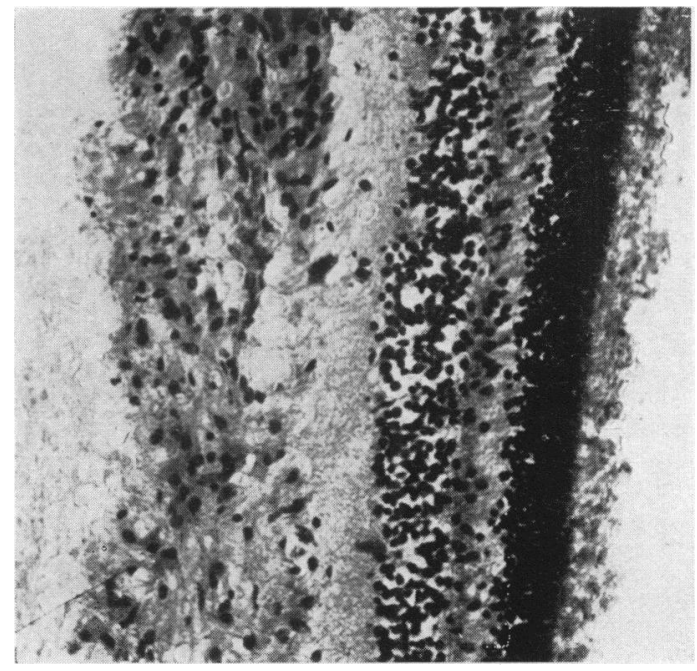

Fig. 15.-Phakoma of the retina in layer of optic nerve fibres. Haematoxylin and eosin. $\times 180$.

consisting of several irregular layers of cells resembling the above. Some collagen and reticulin were also present between the cells, and the 'tumours' could, perhaps, be best described as endothelio-fibromata.

While no phakomata were seen on naked-eye inspection of the retinae, they were present in the histological sections as irregular flattish accumulations of rather uniform glial cells in the layer of optic nerve fibres (Fig. 15).

\section{Discussion}

Fibro-elastosis. The findings in Case 1 were characteristic of endocardial fibro-elastosis; they were definite if less pronounced in Case 2. This association of fibro-elastosis with epiloia has already been mentioned by me in a discussion of the structural features of epiloia (in press) and included in the list of lesions occurring in this condition (Table 1). Fibro-elastosis appears to have been also present in at least two of the previously recorded cases: in Case 15 of the series reported by Critchley and Earl (1932) and in the case published by Norman and Taylor (1940). Further cases of this association may have been easily overlooked, especially as most published accounts of epiloia make little or no mention of organs other than the brain, and it may well be that it will be found more frequently if attention is paid to it in future studies.

Endocardial fibro-elastosis was also sought in association with other conditions in the current series of necropsies and found in two cases of gargoylism and one of dermatomyositis. It is also noteworthy that Henderson, Macgregor, Thannhauser and Holden (1952) seem to have recorded a similar change in the series of gargoylism reviewed by them. They write:

'The endocardium had a normal appearance in most of the specimens, but in six it was thickened and opaque: in one case this change was apparently generalized, in another it was limited to the left auricle, in two to the left ventricle, and in one to both ventricles.'

Thus it would seem that endocardial fibroelastosis, even when it is marked, cannot be regarded as a disease in itself even though there are certain cases in which it is the sole significant abnormality at necropsy. It is suggested, therefore, that the designation, 'endocardial fibro-elastosis', be used to imply a non-specific structural change rather than a disease entity as such.

EPILOIA

\begin{tabular}{|c|c|c|c|c|}
\hline Brain & Skin & Heart & Kidney & Bones \\
\hline $\begin{array}{l}\text { *1. Tuberous sclerosis } \\
\text { *2. Candle guttering } \\
\text { 3. Glioma } \\
\text { 4. Secondary changes, } \\
\text { e.g., demyelination, } \\
\text { softening, etc. }\end{array}$ & \multirow{4}{*}{$\begin{array}{l}\text { *1. Adenoma sebaceum } \\
\text { 2. Peau de chagrin } \\
\text { 3. Flat warts } \\
\text { 4. Haemangioma } \\
\text { 5. Fibroma } \\
\text { 6. Subungual fibroma } \\
\text { 7. Vitiligo } \\
\text { 8. Leucoderma } \\
\text { 9. Café au lait spots }\end{array}$} & $\begin{array}{ll}\text { *1. } & \text { Rhabdomyoma } \\
\text { (Purkinjeoma) } \\
\text { 2. Lipoma. Fibroma }\end{array}$ & $\begin{array}{l}\text { *1. Mixed benign } \\
\text { tumours } \\
\text { 2. Rare malignant } \\
\text { tumours, e.g., car- } \\
\text { cinoma or sarcoma } \\
\text { 3. Polycystic kidney } \\
\text { Teratoma }\end{array}$ & $\begin{array}{l}\text { 1. Periosteal nodules } \\
\text { 2. Osteoporosis } \\
\text { 3. Cysts } \\
\text { 4. Melorheostosis }\end{array}$ \\
\hline \multirow{3}{*}{ Eye } & & Lungs & Other Organs & excrescences \\
\hline & & 1. Congenital Cysts & Haemangioma and & Skeleton \\
\hline & & adenoma & $\begin{array}{l}\text { been mentioned in } \\
\text { thyroid, spleen, } \\
\text { thymus, breast and } \\
\text { duodenum }\end{array}$ & $\frac{1}{\text { 1. Spina bifida }}$ 2. Syndactyly, polydactyly \\
\hline
\end{tabular}

* Common lesions.

Others, rare lesions. 
Perivascular Reticulation. The perivascular lacunation and adventitial hypertrophy in the white matter has been previously discussed by Naidoo (1952) in his account of two cases of gargoylism but has not been observed in epiloia. Its occurrence in one of the present cases is therefore of interest.

Nature of 'Rhabdomyoma'. The nature of the cardiac lesions which are customarily described in the literature as 'rhabdomyomata' is still debatable (Prichard, 1951). I have compared the histological sections of the present cases with the endocardium and myocardium of horses which show numerous normal Purkinje cells and fibres. The similarity between the latter and those in the heart lesions of epiloia is very striking in every respect: situation, size, vacuolation and transverse striation of cytoplasmic bundles. The term 'Purkinjeoma' rather than 'rhabdomyoma' appears therefore more appropriate for the tumour-like accumulation of these cells.

\section{Summary}

Two cases of epiloia showed endocardial fibroelastosis in addition to more familiar changes in the brain and other organs. This association is discussed and it is suggested that the structural change, fibroelastosis, may occur in a number of conditions other than the disease bearing that name, and is not necessarily a disease sui generis. Perivascular reticulation and adventitial hypertrophy were present in the cerebral white matter of one of the cases, a finding not hitherto recorded in epiloia.

I am greatly indebted to my lay and medical colleagues at the Fountain Hospital for their cooperation and access to case records. Mr. J. F. Watt and Mr. J. E. Stevens have assisted in the histological and photographic work.

REFERENCES

Critchley, M. and Earl, C. J. C. (1932), Brain, 55, 311.

Gowing, N. F. C. (1953). J. Path. Bact., 65, 13.

Henderson, J. L., Macgregor, A. R., Thannhauser, S. J. and Holden, R. (1952). Archives of Disease in Childhood, 27, 230.

Naidoo, D. (1952). J. ment. Sci., 99, 74.

Norman, R. M. and Taylor, A. L. (1940). J. Path. Bact., 50, 61.

Prichard, R. W. (1951). Arch. Path., Chicago, 51, 98. 